Atmos. Chem. Phys., 10, 9383-9392, 2010

www.atmos-chem-phys.net/10/9383/2010/

doi:10.5194/acp-10-9383-2010

(C) Author(s) 2010. CC Attribution 3.0 License.

\title{
Terpenylic acid and related compounds: precursors for dimers in secondary organic aerosol from the ozonolysis of $\alpha$ - and $\beta$-pinene
}

\author{
F. Yasmeen ${ }^{1,2}$, R. Vermeylen ${ }^{1}$, R. Szmigielski ${ }^{1,}{ }^{*}$, Y. Iinuma ${ }^{3}$, O. Böge ${ }^{3}$, H. Herrmann ${ }^{3}$, W. Maenhaut ${ }^{4}$, and M. Claeys ${ }^{1}$ \\ ${ }^{1}$ Department of Pharmaceutical Sciences, University of Antwerp, 2610 Antwerp, Belgium \\ ${ }^{2}$ Laboratoire de Radiochimie, Sciences Analytiques et Environnement (LRSAE), Institut de Chimie de Nice \\ (CNRS, FR 3037), University of Nice Sophia-Antipolis, Faculty of Sciences, 06108 Nice, France \\ ${ }^{3}$ Leibniz-Institut für Troposphärenforschung (IfT), 04318 Leipzig, Germany \\ ${ }^{4}$ Department of Analytical Chemistry, Institute for Nuclear Sciences, Ghent University, 9000 Gent, Belgium \\ * present address: Institute of Physical Chemistry of the Polish Academy of Sciences, 01-224, Warsaw, Poland
}

Received: 7 April 2010 - Published in Atmos. Chem. Phys. Discuss.: 23 April 2010

Revised: 20 September 2010 - Accepted: 20 September 2010 - Published: 5 October 2010

\begin{abstract}
In the present study, we have characterized the structure of a higher-molecular weight (MW) $358 \alpha$ - and $\beta$ pinene dimeric secondary organic aerosol (SOA) product that received ample attention in previous molecular characterization studies and has been elusive. Based on mass spectrometric evidence for deprotonated molecules formed by electrospray ionization in the negative ion mode and chemical considerations, it is suggested that diaterpenylic acid is a key monomeric intermediate for dimers of the ester type. It is proposed that cis-pinic acid is esterified with the hydroxyl-containing diaterpenylic acid, which can be explained through acid-catalyzed hydrolysis of the recently elucidated lactone-containing terpenylic acid and/or diaterpenylic acid acetate, both first-generation oxidation products. To a minor extent, higher-MW 358 and 344 diester products are formed containing other terpenoic acids as monomeric units, i.e., diaterpenylic acid instead of cis-pinic acid, and diaterebic acid instead of diaterpenylic acid. It is shown that the MW 358 diester and related MW 344 compounds, which can be regarded as processed SOA products, also occur in ambient fine $\left(\mathrm{PM}_{2.5}\right)$ rural aerosol collected at night during the warm period of the 2006 summer field campaign
\end{abstract}

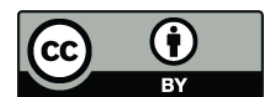

Correspondence to: M. Claeys (magda.claeys@ua.ac.be) conducted at K-puszta, Hungary, a rural site with coniferous vegetation. This indicates that, under ambient conditions, the higher-MW diesters are formed in the particle phase over a longer time-scale than that required for gas-toparticle partitioning of their monomeric precursors in laboratory $\alpha-/ \beta$-pinene ozonolysis experiments.

\section{Introduction}

The formation of higher-molecular weight (MW) products is considered as a driving force for secondary organic aerosol (SOA) formation and growth, because their formation leads to products with a substantially decreased vapor pressure that is several orders of magnitude lower than that of the precursor hydrocarbons. Higher-MW products either correspond to non-covalent dimers between monomeric carboxylic acids that are held together by hydrogen bonds (e.g., Hoffmann et al., 1998; Claeys et al., 2009) or to covalent dimers between monomeric carboxylic acids that are connected through covalent bonds, such as, esters (e.g., Hamilton et al., 2006; Szmigielski et al., 2007; Müller et al., 2008) and oligomers formed through gem-diol intermediates (e.g., Gao et al., 2004; Iinuma et al., 2004; Tolocka et al., 2004; Docherty et al., 2005) or aldol condensation reactions (e.g., Tolocka et al., 2004). These heterogeneous processes are consistent

Published by Copernicus Publications on behalf of the European Geosciences Union. 
with the observation that sulfuric acid seed aerosol catalyzes the formation of SOA (e.g., Jang et al., 2002, 2003; Czoschke et al., 2003; Iinuma et al., 2004).

Structural proposals have been made in previous work for higher-MW SOA products that participate in new particle formation and growth, including dimers and oligomers. The structural elucidation at the molecular level of such compounds is a complex and analytically challenging task as it is only readily feasible if the structures of the composing monomers are known. Conversely, lack of knowledge about the monomeric units has severely hampered structural characterization efforts of higher-MW di- and oligomeric compounds in previous studies.

Considerable attention has been given in previous work to a higher-MW 358 SOA product from $\alpha$-pinene ozonolysis (Hoffmann et al., 1998; Gao et al., 2004; Iinuma et al., 2004), which was first detected by direct negative ion atmospheric pressure chemical ionization - mass spectrometry and tentatively assigned to a stable adduct between cis-pinic (MW 186) and cis-norpinic acid (MW 172), both ozonolysis products (Hoffmann et al., 1998). It was shown in the latter study that the MW 358 compound remained intact upon reversed-phase liquid chromatography; however, a straightforward explanation for the formation of a stable dimer between cis-pinic and cis-norpinic acid was not presented. Following this initial study by Hoffmann et al. (1998), other tentative structures have been proposed for higher-MW $\alpha$-pinene ozonolysis products (Gao et al., 2004; Iinuma et al., 2004; Docherty et al., 2005). Gao et al. (2004) attributed the MW $358 \alpha$-pinene ozonolysis product to a dehydration product formed between the gem-diol forms of two norpinonic acid molecules. Iinuma et al. (2004) reported MW 354 and 370 dimeric products from the ozonolysis of $\alpha$-pinene that were enhanced in acidic conditions and tentatively assigned the products to reaction products between the gem-diol of pinonaldehyde and pinonaldehyde, and of pinonaldehyde and hydroxypinonaldehyde, respectively. Docherty et al. (2005) proposed peroxycarboxylic acid dimers for the structure of higher-MW SOA products from the ozonolysis of $\alpha$-pinene in which peroxypinic acid and the gem-diol of a keto or aldehydic compound are connected via a peroxy bridge. Furthermore, the MW 358 product was detected as a major tracer in other $\alpha$-pinene as well as $\beta$-pinene ozonolysis SOA characterization studies (Iinuma et al., 2007; Müller et al., 2008). In addition, Tolocka et al. (2004) characterized dimers in $\alpha$-pinene ozonolysis SOA and suggested that the dimers were most likely formed by aldol and/or gemdiol formation. Müller et al. (2008) reported the presence of abundant MW 358 and 368 products upon $\alpha$-pinene ozonolysis and provided evidence for esterification of $c i s$-pinic acid with hydroxyl-containing terpenoic acids as a major formation pathway; the MW 370 product was attributed to a diester formed between cis-pinic acid and 10-hydroxypinonic acid but the structure of the MW 358 product remained unresolved. In a more recent study by Müller et al. (2009), the structure of the MW 358 dimer was readdressed and proposed to contain a cis-pinic acid residue and a hydroperoxyhemiacetal or peroxyhemiacetal function, thus involving peroxyradical chemistry. From all these studies it appears that the structure of the MW 358 dimeric product formed upon $\alpha-/ \beta$-pinene ozonolysis has been elusive.

Esterification together with anhydride formation were shown to be important routes for dimer formation from the ozonolysis of cyclohexene (Hamilton et al., 2006). In addition, esterification was shown to operate in the formation of di-, tri-, and tetramers in $\alpha$-pinene ozonolysis based on direct mass spectrometric analysis of complex SOA mixtures and accurate mass measurements that revealed repetitive structures and changes in O:C ratios (Reinhardt et al., 2007). Esterification of small hydroxycarboxylic acids such as hydracrylic, glycolic, lactic, and 2-methylglyceric acid was also found to be a route resulting in isoprene SOA formation (Altieri et al., 2006, 2008; Surratt et al., 2006; Szmigielski et al., 2007; Perri et al., 2009). Furthermore, theoretical calculations by Barsanti and Pankow (2006) show that esterification is a thermodynamically favorable route for SOA formation under atmospheric conditions.

In the present study, we address the structure of a relatively abundant MW 358 compound and related weak MW 344 and 358 compounds that are formed upon $\alpha$ - and $\beta$-pinene ozonolysis and are also present in ambient fine $\left(\mathrm{PM}_{2.5}\right.$, particulate matter with aerodynamic diameter $<2.5 \mu \mathrm{m}$ ) rural continental aerosol. We propose that diaterpenylic acid, a hydrolysis product of terpenylic acid (MW 172) and/or diaterpenylic acid acetate (MW 232), recently reported $\alpha$-pinene SOA tracers formed upon both photooxidation and ozonolysis (Claeys et al., 2009), serves together with cis-pinic acid as a monomeric building unit for the higher-MW 358 diester products.

\section{Experimental}

\subsection{Aerosol samples}

$\alpha$ - and $\beta$-pinene SOA for structural characterization was obtained from ozonolysis experiments carried out in the $19 \mathrm{~m}^{3}$ IfT smog chamber. Briefly, the ozonolysis of $\alpha$ - and $\beta$-pinene was carried out in the presence of acidic seed particles, which were generated by nebulizing a $0.03 / 0.06 \mathrm{M}$ $\left(\mathrm{NH}_{4}\right)_{2} \mathrm{SO}_{4} / \mathrm{H}_{2} \mathrm{SO}_{4}$ solution. The relative humidity and temperature of the chamber were approximately $50 \%$ and $23^{\circ} \mathrm{C}$ for all experiments. The initial concentrations of $\alpha$-pinene and ozone were $100 \mathrm{ppb}$ and $72 \mathrm{ppb}$, respectively. For $\beta$-pinene ozonolysis, the initial concentrations were $300 \mathrm{ppb}$ for $\beta$-pinene and $108 \mathrm{ppb}$ for ozone. No OH scavenger was used in these chamber experiments. Aerosol samples were collected on a $47 \mathrm{~mm}$ PTFE filter (Pall, Fiberfilm) and a volume of $2 \mathrm{~m}^{3}$ of the gaseous reaction mixture was sampled. The filter samples were extracted with methanol $(3 \times 20 \mathrm{~mL})$, 
and the combined methanol extracts were concentrated by rotary evaporation to about $1 \mathrm{~mL}$. Subsequently, the concentrated extracts were filtered over a Teflon filter $(0.45 \mu \mathrm{m})$, then further evaporated under a nitrogen stream and reconstituted in $200 \mu \mathrm{L}$ methanol. For liquid chromatography/mass spectrometry (LC/MS) analysis a part of the samples was diluted with the same volume of water and an aliquot of $5 \mu \mathrm{L}$ was injected. With regard to extraction with methanol, it was verified that this procedure could be applied in the present work. Using a dicarboxylic acid as a model substance (i.e., 1,4-cyclohexanedicarboxylic acid, Sigma-Aldrich, $100 \mathrm{ng}$ ), we have examined in prior tests whether extraction with methanol and further sample workup under our conditions (i.e., solvent removal) results in artifacts such as methyl ester formation; the results show that the mono-ester of 1,4-cyclohexanedicarboxylic acid was formed with a yield of less than 5\%. Since the present study was mainly qualitative, possible artifact methyl ester formation due to extraction with methanol was not considered.

The ambient aerosol samples used in this work were collected from K-puszta, Hungary, during the BIOSOL (Formation mechanisms, marker compounds, and source apportionment for biogenic atmospheric aerosols) campaign between 22 May and 29 June 2006. Information about the site and the sampling campaign is given in the supplement (Sect. 1). Day- and night-time samples were collected using a highvolume dichotomous sampler providing two size fractions, a fine $\left(\mathrm{PM}_{2.5}\right)$ and a coarse size fraction (with aerodynamic diameter $>2.5 \mu \mathrm{m}$ ). A quarter or one eighth (depending on the organic carbon amount) of the $\mathrm{PM}_{2.5}$ quartz fiber filter was extracted with methanol $(3 \times 20 \mathrm{~mL})$, the residue was redissolved in $150 \mu \mathrm{L}$ of a methanol:water $(1: 1, \mathrm{v} / \mathrm{v})$ mixture, and an aliquot of $5 \mu \mathrm{L}$ (corresponding to $5.6 \mu \mathrm{g}$ organic carbon in the case of the selected nighttime sample of 19 June, Fig. 2) was injected for LC/MS analysis.

\subsection{Chemicals}

The terpenoic acid standards used in this work were: cis-pinic acid (purity $>98 \%$; Sigma-Aldrich, St. Louis, MI, USA) and terebic acid (purity $>98 \%$; TCI Europe, Zwijndrecht, Belgium). Terpenylic acid and diaterpenylic acid acetate were available from previous studies (Claeys et al., 2009; Iinuma et al., 2009).

\subsection{LC/MS analysis}

The LC/MS system comprised a Surveyor Plus system (pump and autosampler), a linear ion trap mass spectrometer (LXQ) equipped with an electrospray ionization (ESI) source, and a data system using Xcalibur version 2.0 software (Thermo Scientific, San Jose, USA). A T3 Atlantis C18 column $(3 \mu \mathrm{m} ; 2.1 \times 150 \mathrm{~mm})$ (Waters, Milford, USA) was employed. The mobile phases consisted of acetic acid $0.1 \%$ (v/v) (A) and methanol (B). The applied 80-min gradient elu- tion program was as follows: the concentration of eluent B was kept at $3 \%$ for $2 \mathrm{~min}$, then increased to $90 \%$ in $18 \mathrm{~min}$, kept at $90 \%$ for $43 \mathrm{~min}$, then decreased to $3 \%$ in $5 \mathrm{~min}$, and kept at $3 \%$ for $12 \mathrm{~min}$. The flow rate was $0.2 \mathrm{~mL} \mathrm{~min}^{-1}$. The linear ion trap was operated under the following conditions: sheath gas flow (nitrogen), $0.75 \mathrm{~L} \mathrm{~min}^{-1}$; auxiliary gas flow (nitrogen), $1.5 \mathrm{~L} \mathrm{~min}^{-1}$; source voltage, $-4.5 \mathrm{kV}$; capillary temperature, $350^{\circ} \mathrm{C}$; and maximum ion injection time, $200 \mathrm{~ms}$. For $\mathrm{MS}^{n}(n=2,3$ and 4) experiments, an isolation width of $2 \mathrm{~m} / \mathrm{z}$ units and a normalized collision energy level of $35 \%$ were applied.

\section{Results and discussion}

\subsection{Structural characterization of MW 172, 186, and 232 terpenoic acids}

In this section we deal with the structural characterization of terpenoic acids that serve as monomeric precursors to the dimeric MW 344 and 358 compounds, which will be addressed in the next sections, as well as with the structural characterization of some weak monomeric/isobaric compounds (i.e., compounds with the same elemental composition but a different structure, either a compound with a positional isomeric structure or a non-isomeric compound with different functional groups). Figure $1 \mathrm{a}$ and $\mathrm{b}$ present chromatographic data (base peak chromatograms - BPCs and extracted ion chromatograms - EICs) for SOA from the ozonolysis of $\alpha$ - and $\beta$-pinene, respectively, while Fig. 2 presents chromatographic data for a nighttime $\mathrm{PM}_{2.5}$ aerosol sample from K-puszta. It can be seen that the chromatographic data for $\alpha$ - and $\beta$-pinene SOA are rather similar. The major peak on the $\mathrm{m} / \mathrm{z} 171 \mathrm{EICs}$ with RT $17.3 \mathrm{~min}$ is assigned to the lactone-containing terpenylic acid, a novel terpenoic acid which has only been recently reported (Claeys et al., 2009), based on comparison of its chromatographic and mass spectrometric behaviors with that of a synthesized reference compound. It is noted that terpenylic acid is an isobaric compound of cis-norpinic acid (i.e., a non-isomeric product with the same elemental composition but different functional groups). For comparison reasons (see next section), (-)ESI-MS data for terpenylic acid are presented in Fig. 3a and Scheme 1a. It is noted that the product ions at $\mathrm{m} / z .127$ and 83 are also characteristic for diaterpenylic acid acetate (Claeys et al., 2009) and are also expected to be formed from diaterpenylic acid, produced through hydrolysis of terpenylic acid and diaterpenylic acid acetate (see below). (-)ESI-MS data for diaterpenylic acid acetate are presented in Fig. 3b and Scheme 1b. It can be seen in Fig. 2 that there is also a minor peak on the $\mathrm{m} / z .171 \mathrm{EIC}$ with RT $19.8 \mathrm{~min}$; this peak is attributed to $c i s$-norpinic acid based on detailed interpretation of the (-)ESI-MS data and comparison with LC/MS data reported in the literature (Glasius et al., 2000; Warnke et al., 2006). (-)ESI-MS data for the latter MW 172 compound 

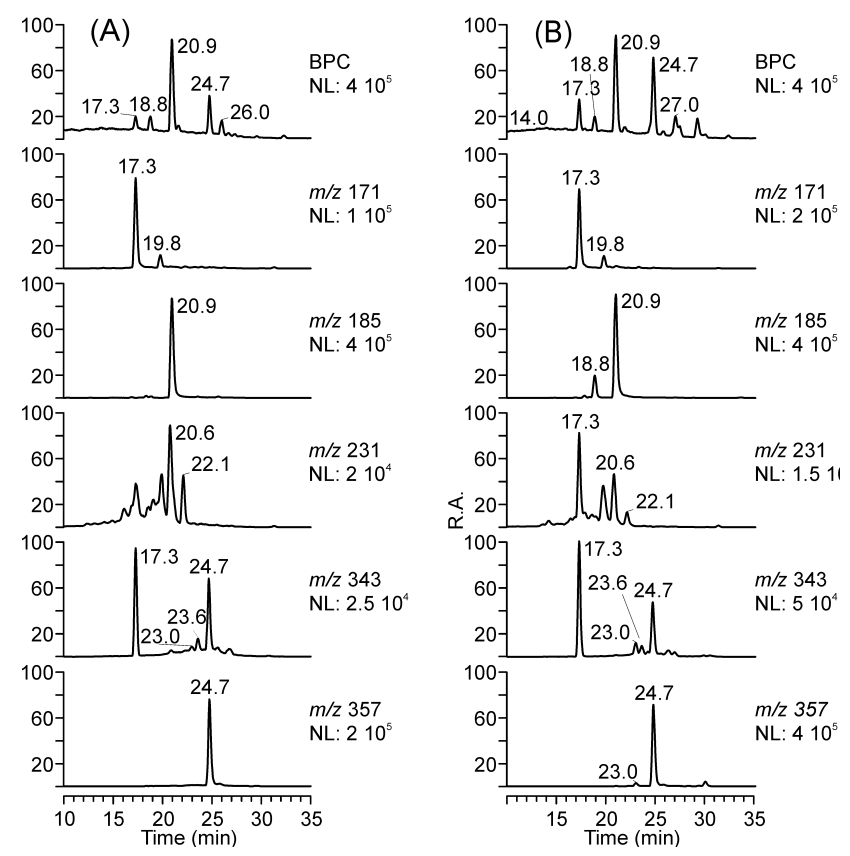

Fig. 1. LC/MS chromatographic data (base peak chromatograms BPCs - and extracted ion chromatograms - EICs) for (A) $\alpha$-pinene and (B) $\beta$-pinene ozonolysis SOA. Abbreviation: NL, normalization level. EICs are presented for $m / z, 171$ (terpenylic acid and isobaric compounds) $\mathrm{m} / \mathrm{z} 185$ (cis-pinic acid and isobaric compounds), $\mathrm{m} / \mathrm{z}, 231$ (diaterpenylic acid acetate and isobaric compounds), $\mathrm{m} / \mathrm{z}$ 343 (MW 344 non-covalent and covalent dimeric compounds) and $\mathrm{m} / z 357$ (MW 358 dimeric compounds).

are given in the supplement (Sect. 2: Fig. S1, Scheme S1). It is likely that in previous work terpenylic acid has often been misassigned to cis-norpinic acid, owing to the fact that the mass spectrometric fragmentation of terpenylic acid shows a double loss of $44 \mathrm{u}\left(\mathrm{CO}_{2}\right)$, indicating the presence of two carboxyl groups and thus rather misleading.

The $m / z$, 185 EIC obtained for $\alpha$ - and $\beta$-pinene ozonolysis SOA (Fig. 1) shows a prominent peak at RT 20.9 min, which is assigned to cis-pinic acid, known to be formed through both ozonolysis and $\mathrm{OH}$ radical-initiated reactions (e.g., Yu et al., 1999; Glasius et al., 2000; Larsen et al., 2001; Winterhalter et al., 2003; $\mathrm{Ng}$ et al., 2007). For comparison reasons (see next section), (-)ESI-MS data for cis-pinic acid are presented in Fig. 3c and Scheme 1c. The second $\mathrm{m} / z 185 \mathrm{com}-$ pound present in $\beta$-pinene ozonolysis SOA at RT $18.8 \mathrm{~min}$ corresponds to a new and specific $\beta$-pinene SOA tracer, which is tentatively identified as a homolog of terpenylic acid, i.e., homoterpenylic acid, based on detailed interpretation of (-)ESI-MS data. (-)ESI-MS data for homoterpenylic acid are presented in Fig. 4 and Scheme 2. Comparison of the MS data obtained for cis-pinic acid (Fig. 3c, Scheme 1c) and homoterpenylic acid (Fig. 4, Scheme 2) show that the isobaric compounds can be differentiated on the basis of the $\mathrm{m} / \mathrm{z} 185 \rightarrow \mathrm{m} / \mathrm{z} 141 \mathrm{MS}^{3}$ product ion spectrum; in the case

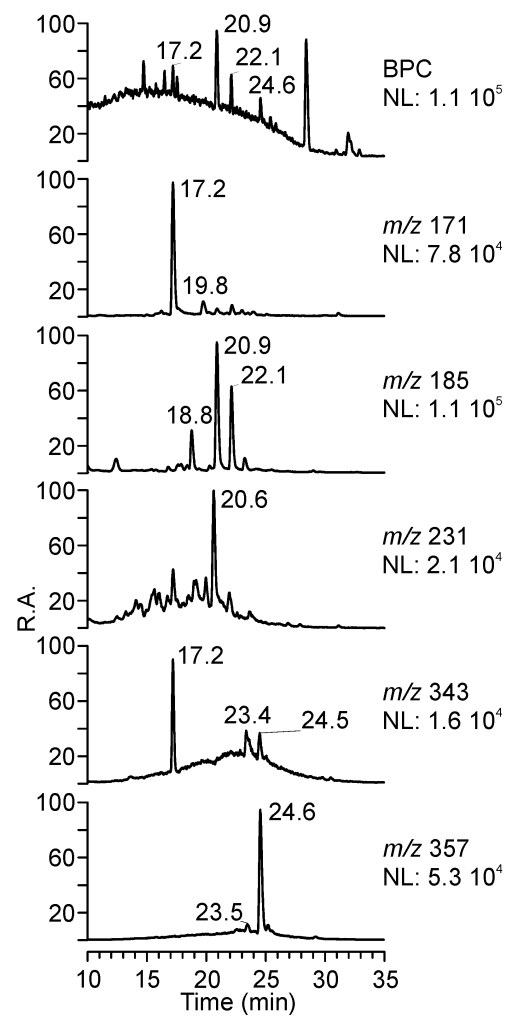

Fig. 2. LC/MS chromatographic data (BPC and EICs) for fine ambient aerosol $\left(\mathrm{PM}_{2.5}\right)$ from K-puszta, Hungary, collected during the night of 19 June 2006 of the warm period of the 2006 summer field campaign. The peak at RT $22.1 \mathrm{~min}$ (not discussed in the main text) on the $\mathrm{m} / \mathrm{z}, 185$ EIC is tentatively assigned to cis-caronic acid, a positional isomer of cis-pinic acid, based on comparison of its chromatographic properties with literature data (Larsen et al., 2001).

of cis-pinic acid fragmentation of $\mathrm{m} / \mathrm{z} 141$ results in $\mathrm{m} / \mathrm{z}$ 99 through loss of $42 \mathrm{u}$ (propene), while in the case of homoterpenylic acid $\mathrm{m} / \mathrm{z}, 141$ produces $\mathrm{m} / \mathrm{z}, 97$ through loss of $44 \mathrm{u}\left(\mathrm{CO}_{2}\right)$. It can also be seen that the relative abundance of $\mathrm{m} / \mathrm{z}, 123$ in the $\mathrm{m} / \mathrm{z}, 185 \mathrm{MS}^{2}$ product ion spectrum is the highest in the case of homoterpenylic acid (i.e., $20 \%$ vs. $2 \%$ for cis-pinic acid). A possible formation pathway of homoterpenylic acid involving reaction of $\beta$-pinene with $\mathrm{OH}$ radicals (which are also generated in the ozonolysis experiments since no $\mathrm{OH}$ scavenger was used), similar to that proposed for terpenylic acid (Claeys et al., 2009), is provided in the supplement (Sect. 3: Scheme S2).

The $m / z 231$ EIC contains four distinct peaks; the first two peaks with RTs 17.3 and $19.8 \mathrm{~min}$ are interpreted as noncovalent adducts formed between acetic acid (present in the LC eluent) and the MW 172 compounds (i.e., terpenylic and cis-norpinic acid), while the last two peaks with RTs 20.6 and 22.1 min correspond to isobaric MW 232 compounds. Of these, the peak with RT $20.6 \mathrm{~min}$ is assigned to diaterpenylic acid acetate, which has recently been reported as a SOA tracer for the photooxidation of 1,8-cineole (Iinuma et al., 


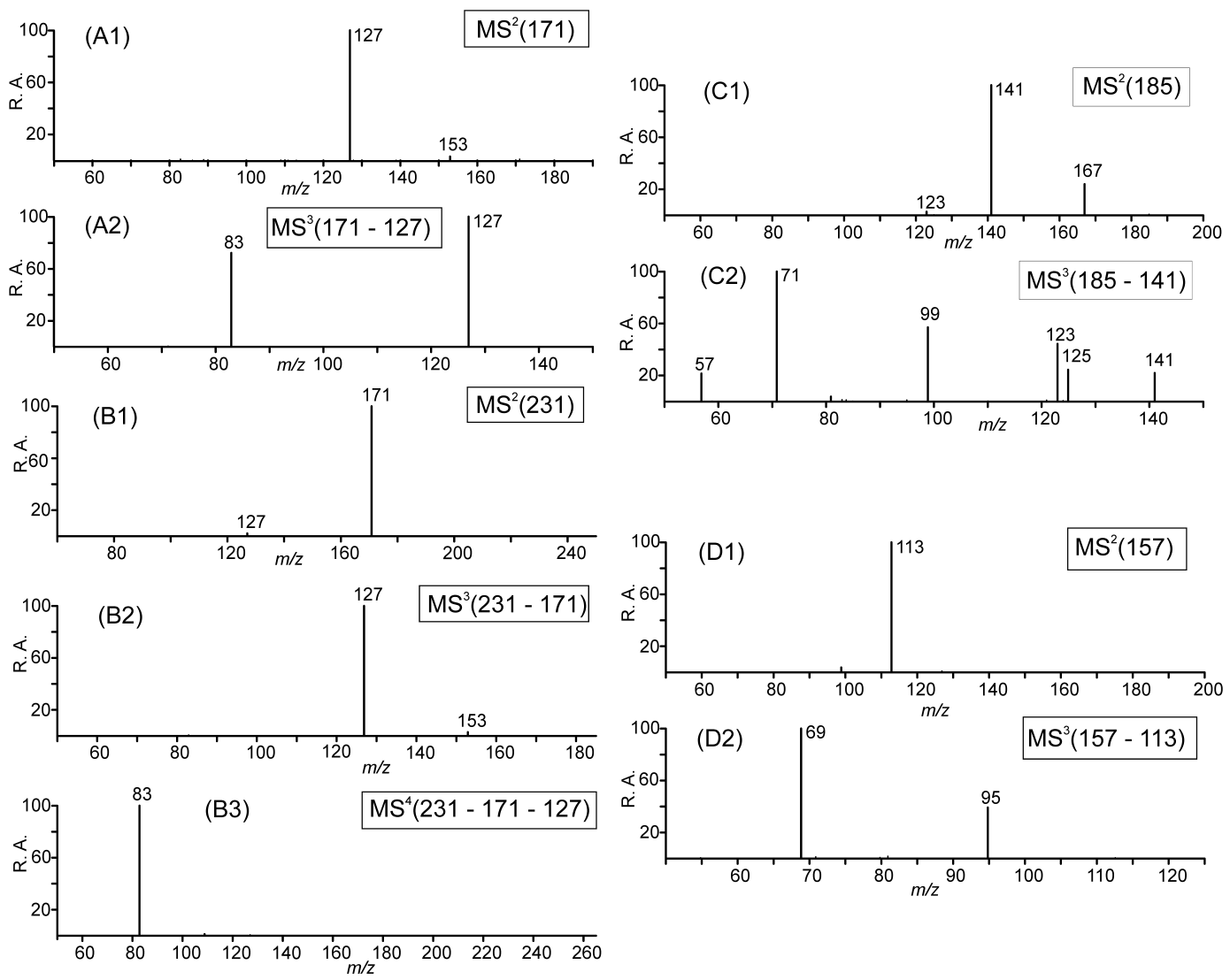

Fig. 3. (-)ESI-MS data for authentic reference compounds of (A) terpenylic acid, (B) diaterpenylic acid acetate, (C) cis-pinic acid, and (D) terebic acid.

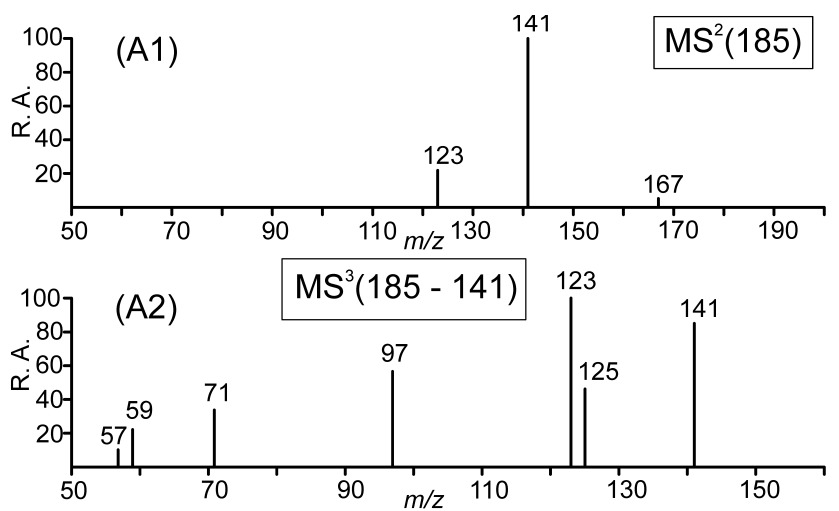

Fig. 4. (-)ESI-MS data for the SOA product formed upon ozonolysis of $\beta$-pinene with RT $18.8 \mathrm{~min}$ (Fig. 1B), tentatively assigned to homoterpenylic acid.

2009) and for the photooxidation and ozonolysis of $\alpha$-pinene (Claeys et al., 2009). The last eluting $\mathrm{m} / \mathrm{z} 231$ compound with RT 22.1 min corresponds to an isobaric compound of diaterpenylic acid acetate, a new compound which still remains to be elucidated. In this respect, it has been reported by Iinuma et al. $(2004,2005)$ that three isomers of a MW 232 compound are detected in $\alpha$-pinene ozonolysis SOA using capillary electrophoresis/(-)ESI-MS. (-)ESI-MS data for the isobaric MW 232 compound with RT $22.1 \mathrm{~min}$ are given in the supplement (Sect. 4: Fig. S2).

Comparison of the chromatographic data for $\alpha$ - and $\beta$ pinene SOA and ambient samples from K-puszta shows the presence of all the terpenoic acids mentioned above in all samples. The data obtained for a nighttime sample of the warm period of the campaign are illustrated in Fig. 2. It is noted that the relatively abundant MW 358 compound $(\mathrm{m} / \mathrm{z}$ 357 ) is only detected in the nighttime samplings of the warm period. Hence, an effort was done to structurally characterize the MW 358 compound and related weak MW 358 and 344 compounds.

\subsection{Structural characterization of MW 358 dimeric compounds}

Figure 5 presents the (-)ESI-MS data for the relatively abundant MW 358 compound that can be detected at RT $24.7 \mathrm{~min}$ in $\alpha$-pinene ozonolysis SOA. Exactly the same product ion data were obtained for the MW 358 compound in the ambient nighttime sample (supplement; Sect. 5: Fig. S3), while some differences were observed for the relatively abundant 
(a)

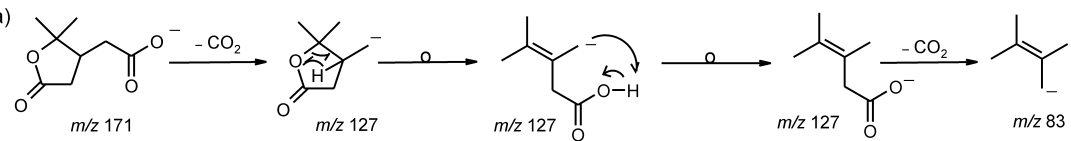

(b)

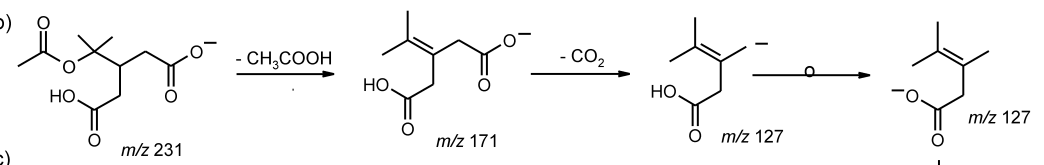

(c)

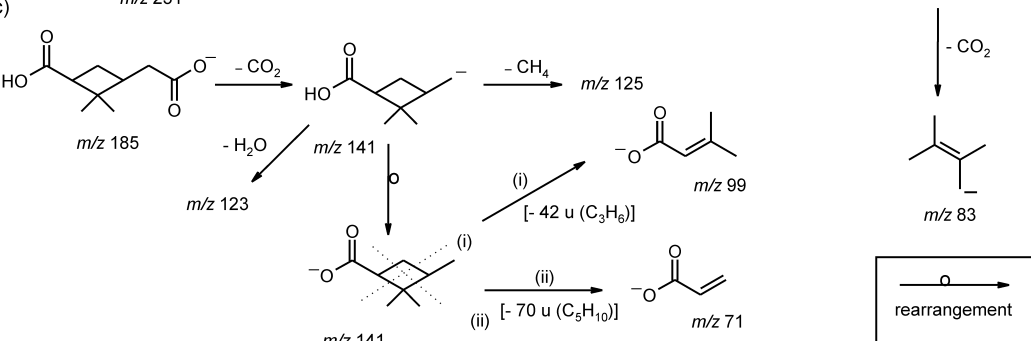

(d)

(e)

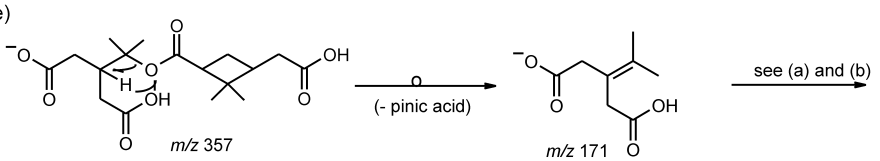

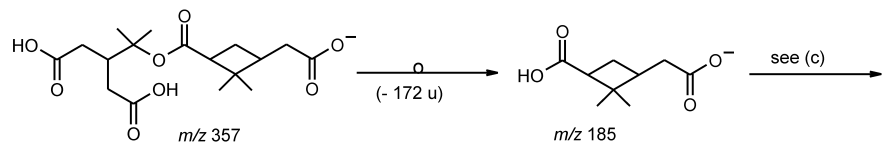

(f)

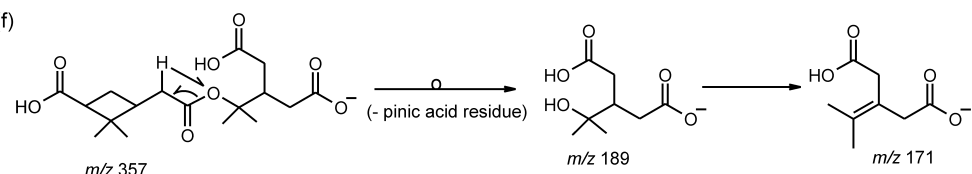

Scheme 1. Proposed (-)ESI-MS fragmentation pathways for deprotonated (a) terpenylic acid, (b) diaterpenylic acid acetate, (c) cis-pinic acid, (d) terebic acid, and the (e) relatively abundant and (f) weak MW 358 compounds.

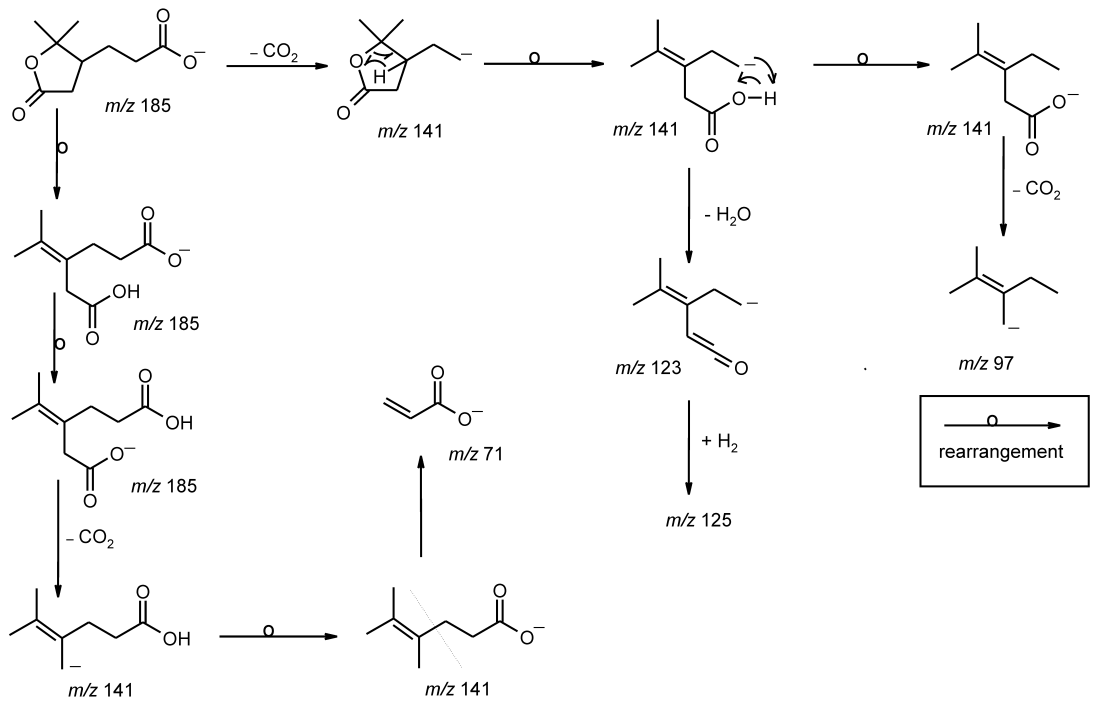

Scheme 2. Proposed (-)ESI-MS fragmentation pathways for deprotonated homoterpenylic acid. 

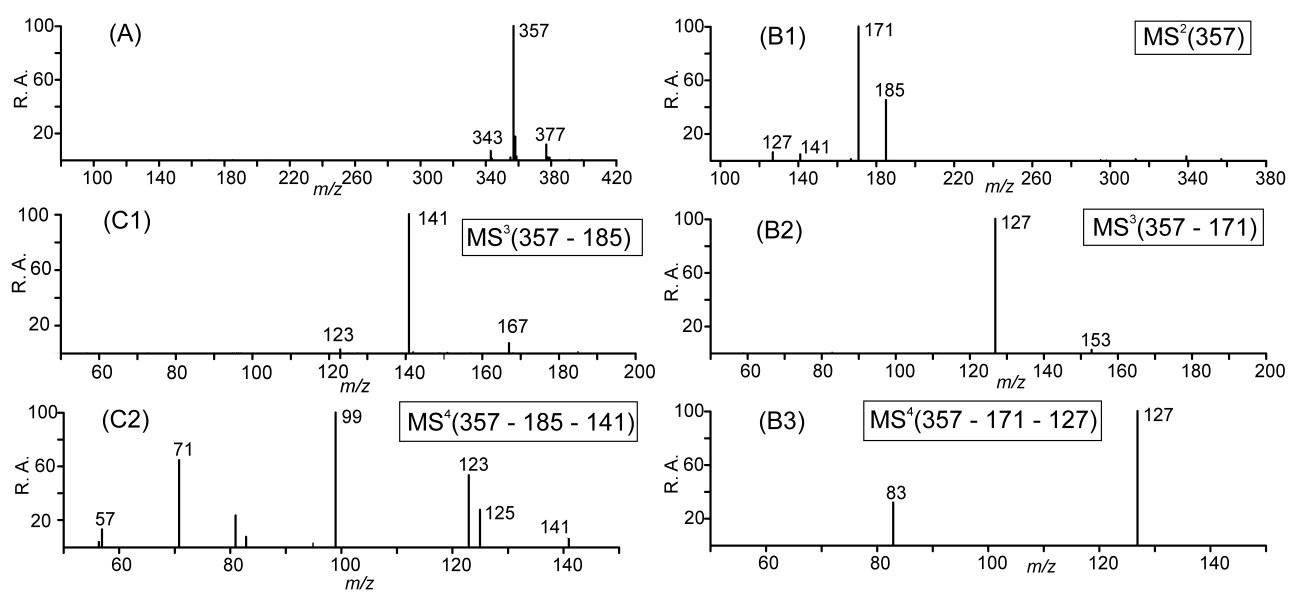

Fig. 5. (-)ESI-MS data for the relatively abundant MW 358 compound (RT 24.7 min; Fig. 1A) present in $\alpha$-pinene ozonolysis SOA, assigned to a covalent dimer of the ester type: (A) first-order mass spectrum; (B1) $\mathrm{m} / z 357 \mathrm{MS}^{2}$ spectrum; (B2) and (B3) $\mathrm{m} / z 357 \rightarrow \mathrm{m} / z .171 \mathrm{MS} n$ $(n=3,4)$ spectra; and, (C1) and (C2) $m / z, 357 \rightarrow m / z, 185 \mathrm{MS}^{n}(n=3,4)$ spectra.
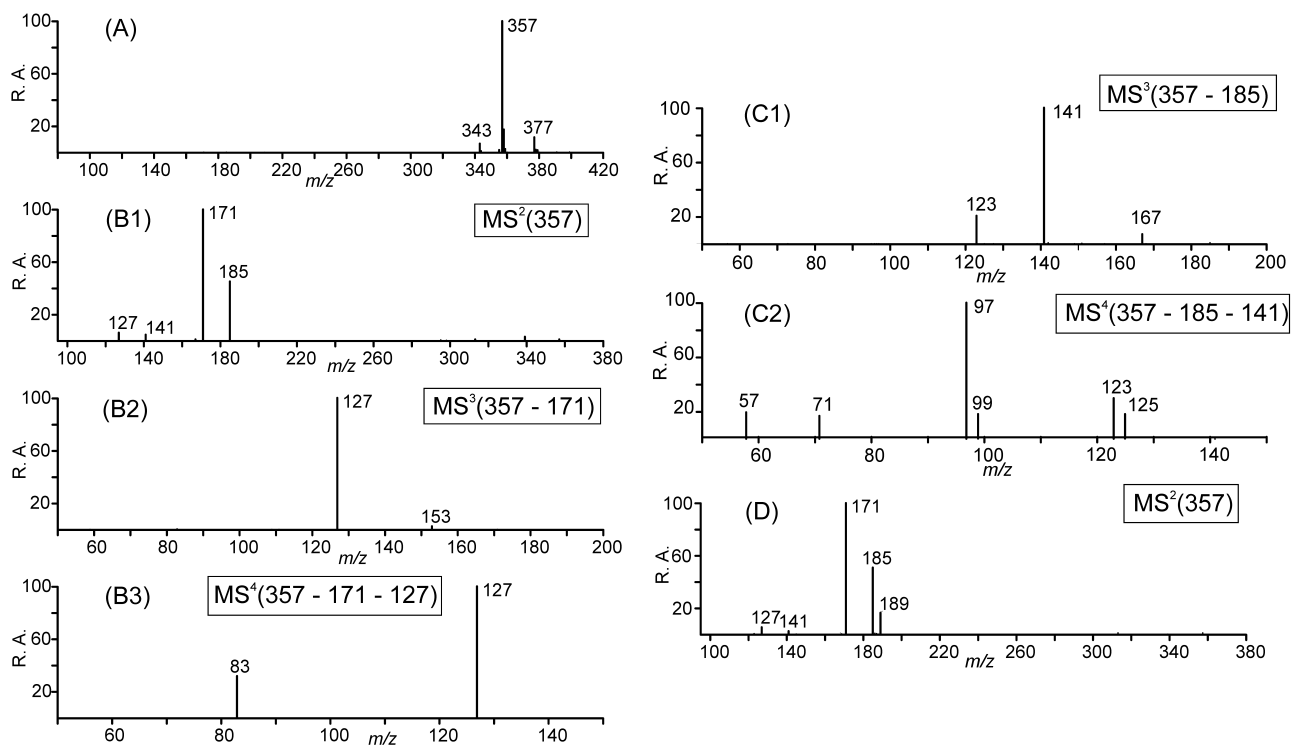

Fig. 6. (-)ESI-MS data for the relatively abundant MW 358 compound (RT 24.7 min; Fig. 1B) present in $\beta$-pinene ozonolysis SOA, assigned to a covalent dimer of the ester type: (A) first-order mass spectrum; (B1) $\mathrm{m} / \mathrm{z} 357 \mathrm{MS}^{2}$ spectrum; (B2) and (B3) $\mathrm{m} / z$ 357 $\rightarrow \mathrm{m} / \mathrm{z}$ $171 \mathrm{MS}^{n}(n=3,4)$ spectra; and, (C1) and (C2) $m / z, 357 \rightarrow m / z 185 \mathrm{MS}^{n}(n=3,4)$ spectra. (D) $\mathrm{m} / z, 357 \mathrm{MS}^{2}$ spectrum for the weak MW 358 compound at RT 23.0 min (Fig. 1B).

MW 358 compound in $\beta$-pinene ozonolysis SOA (Fig. 6) (see below). The relatively abundant higher-MW 358 compound in $\alpha$-pinene ozonolysis SOA is assigned to a covalent dimer of the ester type containing diaterpenylic acid and cispinic acid as monomeric building units, based on mass spectral considerations. The first-order mass spectrum (Fig. 5a) shows in addition to the deprotonated molecule $[\mathrm{M}-\mathrm{H}]^{-}(\mathrm{m} / \mathrm{z}$ $357)$ an ion at $m / z 377$ which could not be assigned and an ion at $\mathrm{m} / \mathrm{z} 343$ due to co-elution of a homologous MW 344 species (see below). The $m / z, 357 \mathrm{MS}^{2}$ spectrum (Fig. 5b1) shows two abundant product ions at $\mathrm{m} / \mathrm{z} 185$ and 171, of which $\mathrm{m} / \mathrm{z}, 185$ upon further fragmentation reveals a pattern (Fig. 5c) comparable to that observed for deprotonated cis- pinic acid (Fig. 3c). Further fragmentation of $\mathrm{m} / \mathrm{z} 171 \mathrm{re}-$ veals a pattern (Fig. 5b) similar to that observed for deprotonated terpenylic acid and for further fragmentation $\left(\mathrm{MS}^{2}\right)$ of $\mathrm{m} / \mathrm{z}, 171$ formed through loss of acetic acid from deprotonated diaterpenylic acid acetate (Fig. 3b). It is noted that there are differences in the relative abundances of the product ions, a feature that can be explained by a different internal energy of the first- $\left(\mathrm{MS}^{2}\right)$ and second-generation $\left(\mathrm{MS}^{3}\right)$ precursor ions. Precursor ions with a higher internal energy will namely result in more extensive fragmentation upon $\mathrm{MS}^{2}$ or $\mathrm{MS}^{3}$ collisional activation experiments. Although (-)ESIMS data are not available for diaterpenylic acid, which is proposed to serve as an intermediate in dimer formation (see 


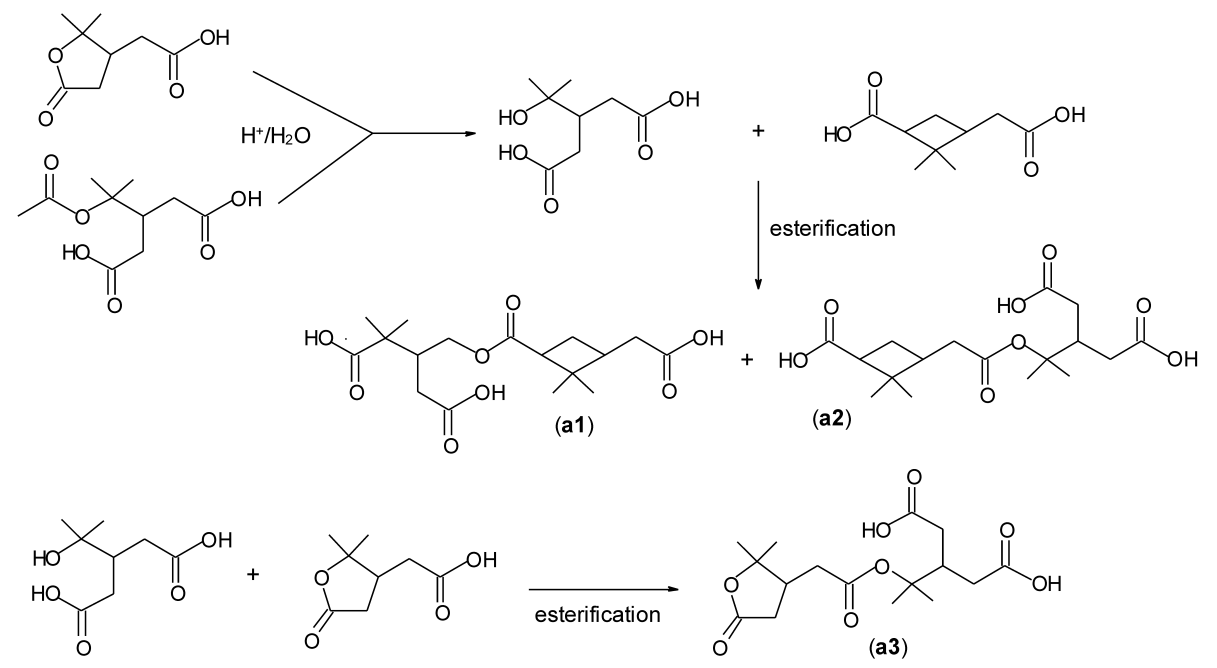

Scheme 3. Proposed formation mechanism for the MW 358 and 344 compounds related to terpenylic acid and diaterpenylic acid acetate.

below), it is expected to result in $\mathrm{m} / \mathrm{z} 171$ through loss of a molecule of water from the deprotonated molecule (similar to the loss of acetic acid from protonated diaterpenylic acid acetate).

The formation of the MW 358 compound can be explained by esterification of cis-pinic acid with diaterpenylic acid, which can be generated as an intermediate by acid-catalyzed hydrolysis of terpenylic acid and/or diaterpenylic acid acetate (Scheme 3). In this respect, it has recently been demonstrated that esterifcation is an important route to the formation of higher-MW products in $\alpha$-pinene ozonolysis SOA and that cis-pinic acid is a key monomeric unit (Müller et al., 2008).

Since cis-pinic acid contains two carboxyl groups, two isomeric diester structures are possible. In order to determine which positional isomeric structure belongs to the relatively abundant MW 358 compound, we also recorded data for the weak MW 358 compound present in $\beta$-pinene ozonolysis SOA at RT $23.0 \mathrm{~min}$ (Fig. 1b). Selected (-)ESI-MS data (i.e., the $m / z 357 \mathrm{MS}^{2}$ spectrum) for the weak MW $358 \mathrm{com}$ pound are given in Fig. 6d. The higher-order $\mathrm{MS}^{n}$ spectra were consistent with diaterpenylic and cis-pinic monomeric units (not shown). Compared to the $m / z 357 \mathrm{MS}^{2}$ spectrum of the relatively abundant MW 358 compound (Fig. 5b1) it can be seen that the spectrum for the weak isomer (Fig. 6d) contains an additional product ion at $\mathrm{m} / \mathrm{z}, 189$. The latter ion is explained by a neutral loss of $188 \mathrm{u}$ corresponding to cispinic acid, which can only readily occur in the isomer where the ester linkage is at the carboxylmethyl side (Scheme 3). On the basis of these considerations structures a1 and a2 are tentatively attributed to the relatively abundant and weak MW 358 compounds, respectively. A possible explanation for the favorable ester formation at the carboxyl (attached to the dimethylcyclobutane ring) instead of the carboxylmethyl side of $c i s$-pinic acid is that there is a lower conformational flexibility at this side, facilitating ester formation.
With respect to differences observed between the relatively abundant MW 358 diester in $\alpha$ - and $\beta$-pinene ozonolysis SOA, it can be seen that the $m / z, 357 \rightarrow m / z, 185$ $\rightarrow m / z, 141 \mathrm{MS}^{4}$ product ion spectrum in the case of $\beta$-pinene shows an additional $\mathrm{m} / \mathrm{z}, 97$ product ion (Fig. 6c2), which is typical for homoterpenylic acid (Fig. 4). It can also be noted that the $m / z 357 \rightarrow m / z 185 \mathrm{MS}^{3}$ product ion spectrum (Fig. 6c1) is more similar to the $m / z, 185 \mathrm{MS}^{2}$ spectrum of homoterpenylic acid (i.e., the relative abundance of $\mathrm{m} / z 123$ is $20 \%$ ). Hence, it cannot be ruled out that the relatively abundant MW 358 diester in $\beta$-ozonolysis SOA contains a major contribution from a dimer formed between diaterpenylic and homoterpenylic acid.

\subsection{Structural characterization of MW 344 dimeric compounds}

The $m / z$ 343 EICs obtained for $\alpha$ - and $\beta$-pinene ozonolysis SOA (Fig. 1) show two major peaks with RTs 17.3 and $24.7 \mathrm{~min}$. The first one is attributed to strong non-covalent dimer formation of terpenylic acid upon (-)ESI-MS, a phenomenon that has been addressed in detail in Claeys et al. (2009) and has been attributed to the presence of one free carboxylic acid group that does not participate in intramolecular hydrogen bonding interactions. It is worth noting that such type of dimer formation is not observed for cis-norpinic acid (RT $19.8 \mathrm{~min}$ ), consistent with the strong non-covalent dimer-forming properties of terpenylic acid. The second major $m / z, 343$ compound is due to a MW 344 compound that co-elutes with the relatively abundant MW 358 compound (Fig. 5a). (-)ESI-MS data are presented in the supplement (Sect. 6: Fig. S4). This MW 344 compound is attributed to a homolog of the relatively abundant MW 358 compound, which can be explained by reaction between diaterebic acid, a homolog of diaterpenylic acid, and cis-pinic acid. A close inspection of the (-)ESI-MS data indeed reveals that the 
precursor of diaterebic acid, terebic acid, is detected at $\mathrm{m} / \mathrm{z}$ 157 (RT $15.8 \mathrm{~min}$ ) with an abundance of about 21\%, 13.9\%, and $85 \%$ of that of terpenylic acid for $\alpha$ - and $\beta$-pinene SOA, and the ambient sample, respectively. (-)ESI-MS data for terebic acid are presented in Fig. 3d and Scheme 1d. Terebic acid can be regarded as a processed derivative of terpenylic acid; its possible formation route through further reaction of terpenylic acid with $\mathrm{OH}$ radicals (aging) is presented in the supplement (Sect. 7: Scheme S3). Similar to terpenylic acid, terebic acid was found to exhibit strong non-covalent dimerforming properties in (-)ESI-MS (not shown). Furthermore, this MW 344 compound could also be detected in the ambient samples of the warm period of the 2006 summer field campaign conducted at K-puszta (not shown).

It can also be seen that the $m / z 343$ EICs for $\alpha$ - and $\beta$ pinene ozonolysis SOA (Fig. 1) show minor signals at RTs 23.0 and $23.6 \mathrm{~min}$. The data obtained for the peak at RT $23.0 \mathrm{~min}$ were similar to those for the major peak at RT 24.7 min (not shown); on the basis of these data this minor peak is attributed to a homolog of the weak MW 358 compound (i.e., the dimer where the diaterebic acid residue is at the carboxylmethyl side of cis-pinic acid). The weak MW 344 compound eluting at RT $23.6 \mathrm{~min}$ is assigned to a dimer of the ester type containing solely terpenylic and diaterpenylic acid units (Scheme 3; structure a3). (-)ESI-MS data for the latter compound are presented in the supplement (Sect. 8: Fig. S5). Similar data were also recorded for the ambient samples of the warm period of the 2006 summer field campaign conducted at K-puszta (not shown).

In addition, we evaluated whether the higher-MW 368 product reported by Müller et al. (2008), which corresponds to a diester formed between cis-pinic acid and 10-hydroxypinonic acid, was present in our samples. We also compared its abundance with that of the relatively abundant 358 compound. The MW 368 compound could be detected at RT $25.9 \mathrm{~min}$ for $\alpha$ - and $\beta$-pinene ozonolysis SOA, and the ambient sample, with an abundance of about $54 \%$, $1.5 \%$, and $54 \%$ of that of the relatively abundant MW 358 compound, respectively. Furthermore, we evaluated whether higher-MW dimers (MW 372) formed between cis-pinic acid and the hydrolysis product of homoterpenylic acid (i.e., diahomoterpenylic acid) could be detected in $\beta$-pinene ozonolysis SOA and the ambient samples considering that homoterpenylic acid is present in these samples, but no evidence could be found for them.

\section{Conclusions}

The results of this study are consistent with terpenylic acid and related terpenoic acids (i.e., diaterpenylic acetate and terebic acid) serving together with cis-pinic acid as monomeric precursors for a relatively abundant MW 358 dimeric compound as well as for structurally related weak MW 358 and 344 compounds in $\alpha-/ \beta$-pinene ozonolysis
SOA. Our study is in line with previous studies (Hamilton et al., 2006; Müller et al., 2008) that provided evidence for esterification being an important route to dimer formation in ozonolysis SOA. Moreover, our study demonstrates that esterification reactions are important to generate higher-MW compounds in ambient aerosol. It is shown that the dimeric $\alpha-/ \beta$-pinene SOA tracers with MWs 358 and 344 could only be detected in the nighttime samplings of the warm period of the 2006 K-puszta summer field campaign. This suggests that their formation in the ambient atmosphere occurs at a relatively high temperature (daily maximum temperature $>24^{\circ} \mathrm{C}$ ) and a long time-scale. This behavior contrasts with the fast formation of the MW 358 diester in $\alpha$ - and $\beta$-pinene ozonolysis experiments, where it is formed concurrently with the corresponding monomeric precursors (Hoffmann et al., 1998; Müller et al., 2008; Gao et al., 2010). A possible reason for this discrepancy could be related to the observation that cis-pinic acid, a monomeric building unit of the higherMW dimers, shows a strong diel variation at the K-puszta forest site and is only present at substantial concentrations in ambient fine nighttime aerosol (Kourtchev et al., 2009). Further work is warranted to define the ambient conditions under which the monoterpene SOA diester products are formed, and to assess their occurrence in other forested environments and their usefulness as SOA tracers.

\section{Supplementary material related to this article is available online at: http://www.atmos-chem-phys.net/10/9383/2010/ acp-10-9383-2010-supplement.pdf.}

Acknowledgements. This study was financially supported by the following organizations: for Universities of Antwerp (UA) and Ghent: Belgian Federal Science Policy Office (BIOSOL project), and Research Foundation - Flanders; and for Leibniz-Institut für Troposphärenforschung: Deutsche Forschungsgemeinschaft.

Edited by: H. Saathoff

\section{References}

Altieri, K. E., Carlton, A. G., Lim, H.-J., Turpin, B. J., and Seitzinger, S. P.: Evidence for oligomer formation in clouds: Reactions of isoprene oxidation products, Environ. Sci. Technol., 40, 4956-4960, 2006.

Altieri, K. E., Seitzinger, S. P., Carlton, A. G., Turpin, B. J., Klein, G. C., and Marshall, A.G.: Oligomers formed through in-cloud methylglyoxal reactions: chemical composition, properties, and mechanisms investigated by ultra-high resolution FT-ICR mass spectrometry, Atmos. Environ., 42, 1476-1490, 2008.

Barsanti, K. C. and Pankow, J. F.: Thermodynamics of the formation of atmospheric organic particulate matter by accretion reactions - Part 3: Carboxylic and dicarboxylic acids, Atmos. Environ., 40, 6676-6686, 2006.

Claeys, M., Iinuma, Y., Szmigielski, R., Surratt, J. D., Blockhuys, F., Van Alsenoy, C., Böge, O., Sierau, B., Gómez-González, Y., 
Vermeylen, R., Van der Veken, P., Shahgholi, M., Chan, A. W. H., Herrmann, H., Seinfeld, J. H., and Maenhaut, W.: Terpenylic acid and related compounds from the oxidation of $\alpha$-pinene: Implications for new particle formation and growth above forest, supporting information available at: http://www.acs.com, Environ. Sci. Technol., 43, 6976-6982, 2009.

Czoschke, N. M., Jang, M., and Kamens, R. M.: Effect of acidic seed on biogenic secondary organic aerosol growth, Atmos. Environ., 37, 4287-4299, 2003.

Docherty, K. S., Wu, W., Lim, Y. B., and Ziemann, P. J.: Contributions of organic peroxides to secondary aerosol formed from reactions of monoterpenes with $\mathrm{O}_{3}$, Environ. Sci. Technol., 39, 4049-4059, 2005.

Gao, S., Ng, N. L., Keywood, M., Varutbangkul, V., Bahreini, R., Nenes, A., He, J., Yoo, K. Y., Beauchamp, J. L., Hodyss, R., Flagan, R. C., and Seinfeld, J. H.: Particle phase acidity and oligomer formation in secondary organic aerosol, Environ. Sci. Technol., 38, 6582-6589, 2004.

Gao, Y., Hall IV, W.A., and Johnston, M. V.: Molecular composition of monoterpene secondary organic aerosol at low mass loading, Environ. Sci. Technol., in press, 2010.

Glasius, M., Lahaniati, M., Calogirou, A., Di Bella, D., Jensen, N. R., Hjorth, J., Kotzias, D., and Larsen, B. R.: Carboxylic acids in secondary aerosols from oxidation of cyclic monoterpenes by ozone, Environ. Sci. Technol., 34, 1001-1010, 2000.

Hamilton, J. F., Lewis, A. C., Reynolds, J. C., Carpenter, L. J., and Lubben, A.: Investigating the composition of organic aerosol resulting from cyclohexene ozonolysis: low molecular weight and heterogeneous reaction products, Atmos. Chem. Phys., 6, 49734984, doi:10.5194/acp-6-4973-2006, 2006.

Hoffmann, T., Bandur, R., Marggraf, U., and Linscheid, M.: Molecular composition of organic aerosols formed in the $\alpha$-pinene $/ \mathrm{O}_{3}$ reaction: Implications for new particle formation processes, J. Geophys. Res., 103, 25569-25578, 1998.

Iinuma, Y., Böge, O., Gnauk, T., and Herrmann, H.: Aerosolchamber study of the $\alpha$-pinene $/ \mathrm{O}_{3}$ reaction: influence of particle acidity on aerosol yields and products, Atmos. Environ., 38, 761-773, 2004.

Iinuma, Y., Böge, O., Miao, Y., Sierau, B., Gnauk, T., and Hermann, H.: Laboratory studies on secondary organic aerosol formation from terpenes, Faraday Discuss., 130, 279-294, 2005.

Iinuma, Y., Müller, C., Berndt, T., Böge, O., Claeys, M., and Herrmann, H.: Evidence for the existence of organosulfates from beta-pinene ozonolysis in ambient secondary organic aerosol, supporting information available at: http://www.acs.com , Environ. Sci. Technol., 41, 6678-6683, 2007.

Iinuma, Y., Böge, O., Keywood, M., Gnauk, T., and Herrrmann, H.: Diaterebic acid acetate and diaterpenylic acid acetate: Atmospheric tracers for secondary organic aerosol formation from 1,8-cineole oxidation, supporting information available at: http: //www.acs.com, Environ. Sci. Technol., 43, 280-285, 2009.

Jang, M. S., Czoschke, N. M., Lee, S., and Kamens, R. M.: Heterogeneous atmospheric aerosol production by acid-catalyzed particle-phase reactions, Science, 298, 814-817, 2002.

Jang, M., Lee, S., and Kamens, R. M.: Organic aerosol growth by acid-catalyzed heterogeneous reactions of octanal in a flow reactor, Atmos. Environ., 37, 2125-2138, 2003.

Kourtchev, I., Copolovici, L., Claeys, M., and Maenhaut, W.: Characterization of aerosols at a forested site in central Europe, sup- porting information available at: http://www.acs.com, Environ. Sci. Technol., 43, 4665-4671, 2009.

Larsen, B. R., Di Bella, D., Glasius, M., Winterhalter, R., Jensen, N. R., and Hjorth, J.: Gas-phase $\mathrm{OH}$ oxidation of monoterpenes: gaseous and particulate products, J. Atmos. Chem., 38, 231-276, 2001.

Müller, L., Reinnig, M.-C., Warnke, J., and Hoffmann, Th.: Unambiguous identification of esters as oligomers in secondary organic aerosol formed from cyclohexene and cyclohexene $/ \alpha$ pinene ozonolysis, Atmos. Chem. Phys., 8, 1423-1433, doi:10.5194/acp-8-1423-2008, 2008.

Müller, L., Reinnig, M.-C., Hayen, H., and Hoffmann, T.: Characterization of oligomeric compounds in secondary organic aerosol using liquid chromatography coupled to electrospray ionization Fourier transform ion cyclotron resonance mass spectrometry, Rapid Commun. Mass Spectrom., 23, 971-979, 2009.

Ng, N. L., Chhabra, P. S., Chan, A. W. H., Surratt, J. D., Kroll, J. H., Kwan, A. J., McCabe, D. C., Wennberg, P. O., Sorooshian, A., Murphy, S. M., Dalleska, N. F., Flagan, R. C., and Seinfeld, J. H.: Effect of $\mathrm{NO}_{\mathrm{x}}$ level on secondary organic aerosol (SOA) formation from the photooxidation of terpenes, Atmos. Chem. Phys., 7, 5159-5174, doi:10.5194/acp-7-5159-2007, 2007.

Perri, M. J., Seitzinger, S., and Turpin, B. J.: Secondary organic aerosol production from aqueous photooxidation of glycolaldehyde: laboratory experiments, Atmos. Environ., 43, 1487-1497, 2009.

Reinhardt, A., Emmenegger, C., Gerrits, B., Panse, C., Dommen, J., Baltensperger, U., Zenobi, R., and Kalberer, M.: Ultrahigh mass resolution and accurate mass measurements as a tool to characterize oligomers in secondary organic aerosols, Anal. Chem., 79, 4074-4082, 2007.

Surratt, J. D., Murphy, S. M., Kroll, J. H., Ng, N. L., Hildebrandt, L., Sorooshian, A., Szmigielski, R., Vermeylen, R., Maenhaut, W., Claeys, M., Flagan, R. C., and Seinfeld, J. H.: Chemical composition of secondary organic aerosol formed from the photooxidation of isoprene, J. Phys. Chem. A, 110, 9665-9690, 2006.

Szmigielski, R., Surratt, J. D., Vermeylen, R., Szmigielska, K., Kroll, J. H., Ng, N. L., Murphy, S. M., Sorooshian, A., Seinfeld, J. H., and Claeys, M.: Characterization of 2methylglyceric acid oligomers in secondary organic aerosol from the photooxidation of isoprene using trimethylsilylation and gas chromatography/ion trap mass spectrometry, J. Mass Spectrom., 42, 101-116, 2007.

Tolocka, M. P., Jang, M., Ginter, J. M., Cox, F. J., Kamens, R. M., and Johnston, M. V.: Formation of oligomers in secondary organic aerosol, supporting information available at: http://www. acs.com, Environ. Sci. Technol., 38, 1428-1434, 2004.

Warnke, J., Bandur, R., and Hoffmann, T.: Capillary-HPLC-ESIMS/MS method for the determination of acidic products from the oxidation of monoterpenes in atmospheric aerosol samples, Anal. Bioanal. Chem., 385, 34-45, 2006.

Winterhalter, R., Van Dingenen, R., Larsen, B. R., Jensen, N. R., and Hjorth, J.: LC-MS analysis of aerosol particles from the oxidation of $\alpha$-pinene by ozone and $\mathrm{OH}$-radicals, Atmos. Chem. Phys. Discuss., 3, 1-39, doi:10.5194/acpd-3-1-2003, 2003.

Yu, J., Cocker III, D. R., Griffin, R. J., Flagan, R. C., and Seinfeld, J. H.: Gas-phase ozone oxidation of monoterpenes: Gaseous and particulate products, J. Atmos. Chem., 34, 207-258, 1999. 